УДК 69.058 .8

\title{
ОПРЕДЕЛЕНИЕ ПАРАМЕТРОВ ЖИВУЧЕСТИ ЗАЩИЩЕННЫХ ОТВЕТСТВЕННЫХ СТРОИТЕЛЬНЫХ КОНСТРУКЦИЙ ПРИ УДАРНО-ВОЛНОВОМ НАГРУЖЕНИИ
}

\author{
Однокопылов Георгий Иванович', \\ OGlz@yandex.ru
}

Кумпяк Олег Григорьевич²,

Галяутдинов Заур Рашидович²,

GaZR@yandex.ru

\author{
Галяутдинов Дауд Рашидович², \\ DaudG@yandex.ru \\ 1 Национальный исследовательский Томский политехнический университет, \\ Россия, 634050, г. Томск, пр. Ленина, 30. \\ 2 Томский государственный архитектурно-строительный университет, \\ Россия, 634003, г. Томск, пл. Соляная, 2.
}

\begin{abstract}
Актуальность работы связана с тенденцией возникновения чрезвычайных ситуаций аварийного характера на предприятиях нефтегазовой промышленности. В связи с чем необходимо проектировать железобетонные конструкций, на которые возможно воздействие интенсивных кратковременных динамических нагрузок аварийного типа, носящих ударно-волновой характер. Учет реакции распора при проектировании позволяет выявить скрытые запасы несущей способности в изгибаемых железобетонных конструкциях, а также снизить трещинообразование, за счет увеличения жесткости. Эффективным способом снижения величины динамического воздействия является применение податливых опор в виде сминаемых вставок кольцевого сечения. Таким образом, совместное применение податливых опор и учет реакции распора дает возможность предотвратить повреждения, полное или частичное разрушение конструкций. Кроме того, повреждения строительных конструкций ответственных зданий и сооружений нефтегазового комплекса приводят к остановке технологического процесса, что в ряде случаев не только экономически не выгодно, но и недопустимо, а также может привести к значительному материальному ущербу и гибели людей.

Цель: разработать методику и алгоритм построения энергетической диаграммы, выполнить числовую оценку применения податливых опор на живучесть защищенных строительных конструкций при интенсивном нагружении

Методы: экспериментальные исследования: реакция входного силового воздействия, реакция выходного силового воздействия, ускорения, перемещения методами тензометрии, численное интегрирование методом Симпсона.

Результаты. Разработана методика и алгоритм построения усредненной энергетической диаграммы. Выполнена числовая оценка применения податливых опор на живучесть защищенных строительных конструкций сооружений нефтегазового комплекса при кратковременном динамическом нагружении.
\end{abstract}

\section{Ключевые слова:}

Живучесть, защищенная строительная конструкция, энергетическая диаграмма, коэффициент результирующей силы, кратковременное динамическое нагружение, ударно-волновое нагружение, железобетон, распор, податливые опоры, силы инерции, экспериментальные исследования.

\section{Актуальность исследования}

При эксплуатации объектов нефтегазовой отрасли всегда существует возможность возникновения серьезных чрезвычайных происшествий, аварий, технических инцидентов, а также несчастных случаев, в том числе со смертельным исходом. Подобные процессы, как правило, проявляются в форме разрушения или значительного повреждения зданий и сооружений [1-5]. Происходит это обычно из-за взрывных процессов и последующих выбросов горячих и токсичных веществ, которые зачастую не поддаются контролю.

На территории РФ природный газ применяется в качестве одного из самых доступных и дешевых источников топлива для функционирования электростанций, теплоцентралей, котельных и компрессорных, что требует повсеместного строительства объектов газовой промышленности. Возни- кновение аварийной ситуации приводит к выходу объекта из строя и последующей приостановке или полному прекращению газоснабжения.

Основными техническими причинами аварий объектов нефтегазовой промышленности можно считать: повреждения и дефекты в конструкциях зданий, технические проблемы с оборудованием, отклонения от проектных решений в процессе строительства и монтажа опасного производственного объекта, высокий износ оборудования, недостаточный уровень внедрения новых технологий, низкое оснащение производства автоматическими системами, активность коррозионных процессов, низкий уровень средств оперативной связи и сигнализации.

Поэтому авторами предложено применение защищенных строительных конструкций в составе объектов нефтегазового комплекса с обеспечением 
и контролем степени живучести при действии ударно-волнового нагружения, не приводящего к полному разрушению строительной конструкции, с возможностью ее дальнейшей эксплуатации.

Повышенное внимание при проектировании объектов данной отрасли должно уделяться совершенствованию методов расчета и анализу напряженно-деформированного состояния строительных конструкций зданий и сооружений при воздействии кратковременных динамических нагрузок аварийного характера [6-18].

В процессе анализа аварийных кратковременных динамических воздействий, необходимого для выработки оптимальных конструктивных решений зданий и сооружений, существуют трудности по определению параметров действующей нагрузки и выявлению истинных коэффициентов запаса прочности конструкций.

Применение методов теории живучести технических систем [19-27] и статических и динамических оценок функционирования объектов позволяет точнее определить остаточный ресурс строительных конструкций, а также зданий и сооружений после воздействий сверхнормативных динамических нагрузок.

Известные методы оценки для статических нагрузок хорошо проработаны. При действии кратковременных динамических нагрузок и оценке всех параметров должно быть учтено время воздействия, а следовательно, необходимо осуществлять контроль изменения всех факторов в процессе времени воздействия, что создает определенные сложности по применению стандартных методов, используемых при статических нагружениях [28-31].

В работе представлена методика оценки живучести защищенных ответственных строительных конструкций нефтегазового комплекса при интенсивном динамическом нагружении. В качестве примера приведен анализ результатов испытаний железобетонной балки при действии кратковременной динамической нагрузки, а также железобетонной балки с распором на податливых опорах при действии кратковременной динамической нагрузки. Для оценки живучести конструкций впервые были получены следующие коэффициенты: коэффициент силового воздействия $k_{F_{d e}}$; энергетический коэффициент $k_{E \text {,med }}$, коэффициента энергоемкости податли-

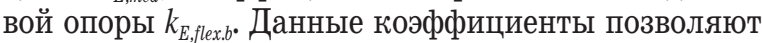
провести численный анализ испытаний конструкций и подтвердить положительное влияние использования податливых опор и учета распора.

При проведении практически любых испытаний на динамическую нагрузку (с видами воздействий: взрывное, ударное, сейсмическое) предполагается наличие узлов входного и выходного контроля параметров действующей нагрузки. Как правило, это различные силоизмерители тензометрического типа.

При обработке экспериментальных результатов использована методика оценки параметров разрушающей нагрузки при ударно-волновом нагружении [32] для ответственных строительных конструкций. В статье представлены результаты испытаний изгибаемых железобетонных балок при действии кратковременной динамической нагрузки в условии ограниченного горизонтального смещения на податливых опорах. Все реальные изгибаемые конструкции (плиты, балки, ригеля) (рис. 1) имеют в опорной части связи (заанкеривание элементов на опорах, замоноличивание зазоров между торцами элементов), которые препятствуют горизонтальному смещению опорных сечений при нагружении и приводят к возникновению распора и соответственно увеличению несущей способности.

При динамическом воздействии влияние распора на сопротивление конструкций неоднозначно: с одной стороны, наличие горизонтальной реакции повышает несущую способность элемента, а с другой - снижает его деформативность, что ведет $\kappa$ снижению пластической стадии деформирования. Данный вопрос рассмотрен в работах: Н.Н. Попова и Б.С. Расторгуева [33-36], Т.Н. Виноградовой [37], А.М. Зулуева [38, 39], И.Н. Тихонова [40, 41], L. Huynh [42], О.Г. Кумпяка, 3.P. Галяутдинова, Д.Р Галяутдинова [43]. Явление распора необходимо учитывать, так как при действии нагрузок аварийного характера в конструкциях в ряде случаев допускается работа арматуры за пределами упругости, что приводит к увеличению деформаций растянутой зоны и, соответственно, росту горизонтальной реакции.

Использование податливых опор приводит к повышению сопротивления конструкций зданий и сооружений действию динамических нагрузок. Результаты экспериментальных исследований изгибаемых конструкций [44-52] на податливых опорах показывают высокую эффективность их применения при действии динамических нагрузок большой интенсивности. При этом наибольший эффект наблюдается при деформировании опор в упругопластической стадии.

Таким образом, использование податливых опор и учет ограничения горизонтального смещения для строительных конструкций требует дальнейшего изучения и с целью применения в промышленных зданиях и сооружениях, в том числе в нефтегазовом комплексе.

В работе применялись средства для обеспечения защиты строительных конструкций при нагрузках аварийного характера. Необходимо отметить, что развитие реакции распора в реальных конструкциях реализуется автоматически при деформировании, за счет наличия элементов, ограничивающих смещения опорной зоны в горизонтальном направлении. Наличие податливой опоры и своевременная замена после исчерпания несущей способности дает возможность поглощения энергии удара, обеспечения живучести конструкции и возможность дальнейшей эксплуатации. 

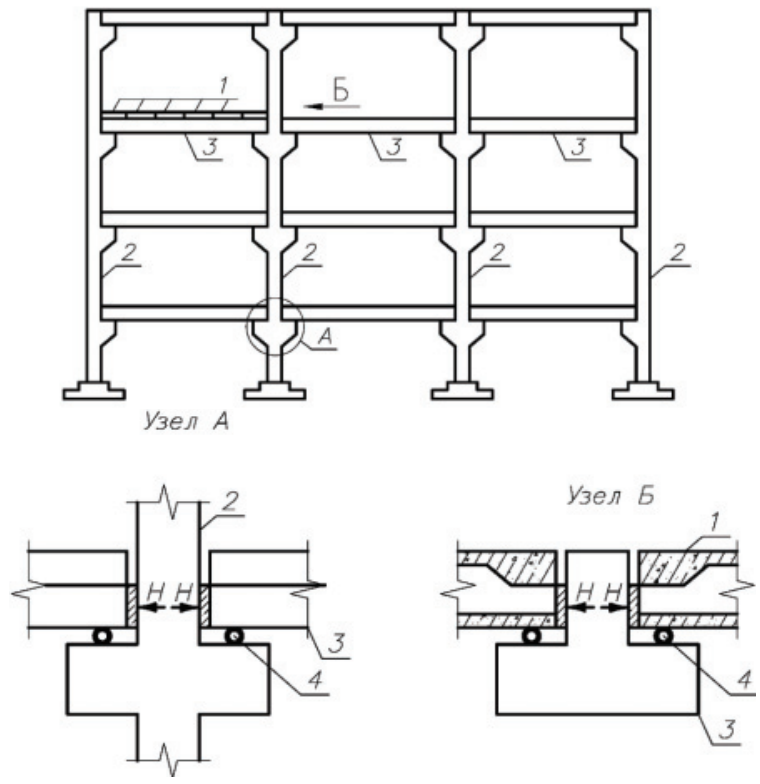

Pис. 1. Типичный узел сопряжения строительных конструкций с применениел податливых опор и учетол реакиии распора: 1 - железобетонная плита; 2 - железобетонная колонна; 3-железобетонный риель; 4 - податливая опора

Fig. 1. Typical coupling assembly of building structures using ductile supports and considering the reaction thrust: 1 is the reinforced concrete slab; 2 is the reinforced concrete column; 3 is the reinforced concrete riel; 4 is the yielding support

\section{Экспериментальные исследования}

Для оценки параметров нагружения и напряженно-деформированного состояния железобетонных балок при интенсивном динамическом нагружении были произведены испытания двух конструкций: БД-1 и БДРП-2. Шифр образца балки указывает на следующие параметры: тип нагружения "Д» - интенсивное динамическое; наличие распора «Р»; наличие податливых опор «П». Например, балка БДРП-2 расшифровывается как балка «Б», испытанная динамической нагрузкой «Д» с учетом распора «Р» на податливых опорах «П». Таким образом в представленных испытаниях варьировалось наличие распора и податливых опор.

Армирование выполнено пространственным каркасом как для образца БД-1, так и для БДРП-2. В качестве поперечной арматуры использована холоднодеформированная арматура $\varnothing 5$ мм класса Вр500, установленная с шагом 50 мм в приопорной зоне и 130 мм в середине пролета; а в качестве продольной - горячекатаная арматура $\varnothing 6$ мм класса А240 в сжатой зоне и $\varnothing 10$ мм класса А500 в растянутой зоне. Для усиления торцовых участков балок использованы сетки с ячейкой $50 \times 50$ мм из холоднодеформированной арматуры $\varnothing 5$ мм класса Вр500 по 7 сеток с каждой стороны и установлен уголок $100 \times 10$ мм.

Для испытаний на конструкции (поз. 1) был размещен комплекс измерительных приборов (рис. 2):
- для определения перемещений - индуктивные датчики перемещения Waycon серии RL150 (поз. 2);

- для измерения ускорений - акселерометры (DHE 100023) (поз. 3);

- для определения входного силового воздействия - датчик силоизмерительный тензоризисторный ДСТ 4126 (поз. 4);

- для определения выходного силового воздействия - датчик силоизмерительный тензоризисторный ДСТ 4126 в количестве 2 шт. на каждую опору (поз. 5).

Для реализации экспериментальных исследований был разработан и изготовлен стенд (рис. 3).

Испытываемая железобетонная балка устанавливается на динамометрические опоры, обеспечивающие шарнирное опирание. Опоры закрепляются на силовом полу, затем создается начальное продольное усилие (распор) гидродомкратом через систему траверс, соединенных направляющими (рис. 3). Податливые опоры размещались в опорных устройствах (рис. 2). Нагрузка прикладывалась в третях пролета, через распределительную траверсу, для выделения зоны чистого изгиба и разрушения по нормальному сечению, согласно рекомендациям ГОСТ 10180-2012.

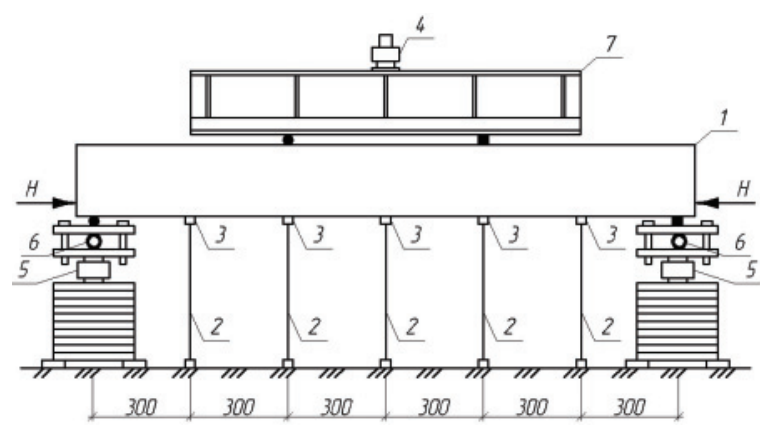

Pис. 2. Схела расстановки измерительных приборов при испьтании железобетонных балок (конструкиия, обеспечивающая развитие реакции распора $H$, условно не показана): 1 - железобетонная балка; 2 - датчики перемещения; 3 - акселерометры; 4 - силоизмеритель для измерения входного силового воздействия; 5 - силоизмеритель для измерения выходного силового воздействия (опорной реакиии); 6 - податливая опора; 7 - распределительная траверса

Fig. 2. Scheme of arrangement of measuring instruments for testing reinforced concrete beams (the design providing the development of the reaction of the thrust $H$ is not shown ): 1 is the reinforced concrete beam; 2 are the displacement sensors; 3 are the accelerometers; 4 is the dynamometer for measuring the input force; 5 is the dynamometer for measuring the output force action (reference reaction ); 6 is the yielding support; 7 is the distribution traverse

Визуализации картины развития трещин в момент достижения предельной нагрузки в процессе кратковременного динамического нагружения выполнена с применением высокоскоростной камеры Photron Fastcam SA-2 c частотой съемки 2500 кад/с (рис. 4, a).

Датчик для измерения нагрузки, создаваемой падающим грузом, устанавливался по центру ра- 


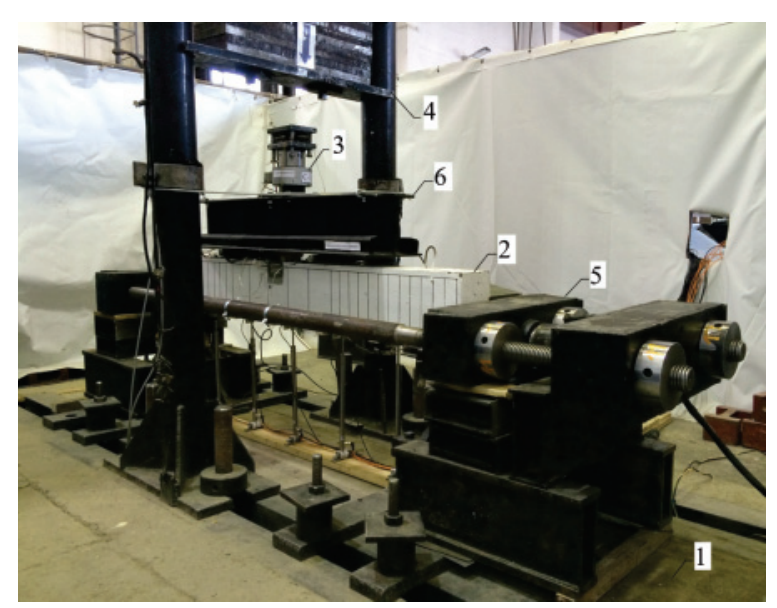

спределительной траверсы сверху образца. С целью увеличения времени действия нагрузки на датчик сверху устанавливался комплект резиновых прокладок (их наличие, толщина и количество обусловлено целями конкретного исследования). Датчики для измерения опорных реакций устанавливались попарно в каждую из специально сконструированных опор. Общий вид измерительного оборудования приведен на рис. 4 .
Pис. 3. Стенд для испытания железобетонных балок при динамическом нагружении с распором на податливых опорах: 1 - силовой пол; 2 - железобетонная балка; 3 - силомер для определения входного силового воздействия; 4 - груз; 5 - ограничительный контур, представленный двумя тяжами, соединенными между собой траверсами, для включения в работу реакиии распора (H); 6 - распределительная траверса

Fig. 3. Stand for testing reinforced concrete beams under dynamic loading with a spread on flexible bearings: 1 is the power field; 2 is the reinforced concrete beam; 3 is the dynamometer for determining the input power action; 4 is the cargo; 5 is the limiting circuit shown two strands interconnected by cross members to enable the work of the thrust reaction $(H) ; 6$ is the distributive traverse

Для регистрации показаний датчиков в процессе экспериментальных исследований использовались сертифицированные измерительные системы MIC-036R и MIC-300M (рис. 5), все датчики были подключены к ним через экранированные кабели.

\section{Результаты экспериментальных данных}

После проведения эксперимента зарегистрированные данные со всех измерительных приборов преобразовывались в формат Microsoft Excel с по-

a/a)
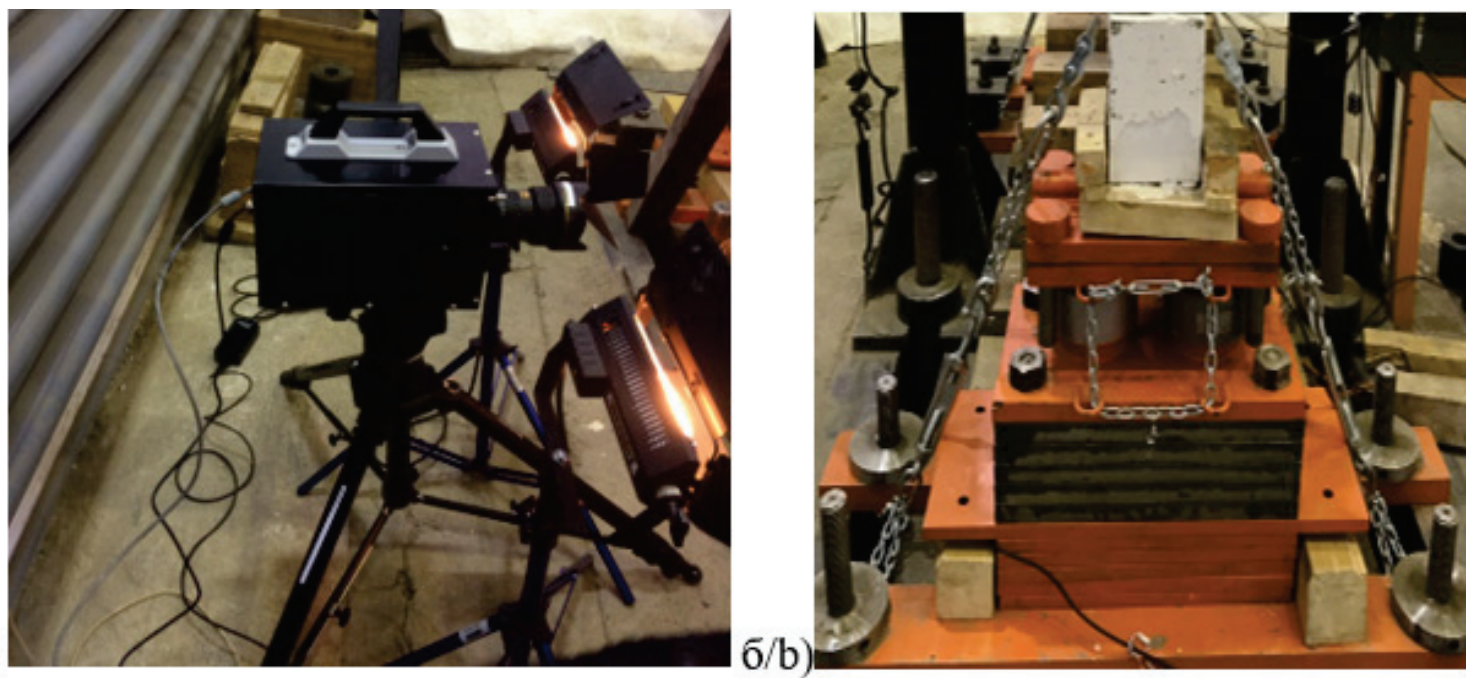

$\mathrm{B} / \mathrm{c})$
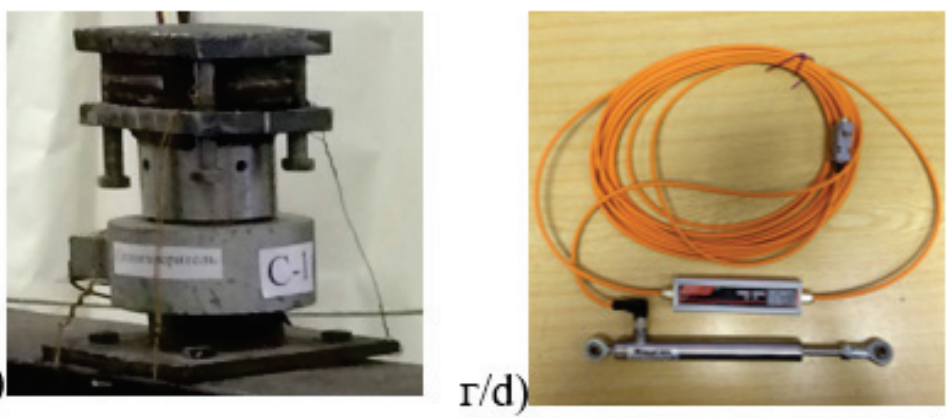

д/e)

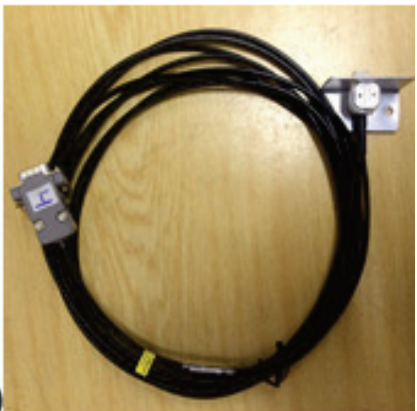

Puс. 4. Общий вид измерительного оборудования: а) высокоскоростная камера Photron Fastcam SA-2; б) конструкиия для измерения выходного силового воздействия (опорной реакиии); в) силоизмеритель для излерения входного силового воздействия; г) датчик перемещения; д) акселерометр

Fig. 4. General view of measuring equipment: a) high-speed camera Photron Fastcam SA-2; b) design for measuring the output force action (reference reaction), c) dynamometer for measuring the input force action; d) displacement sensor accelerometer 


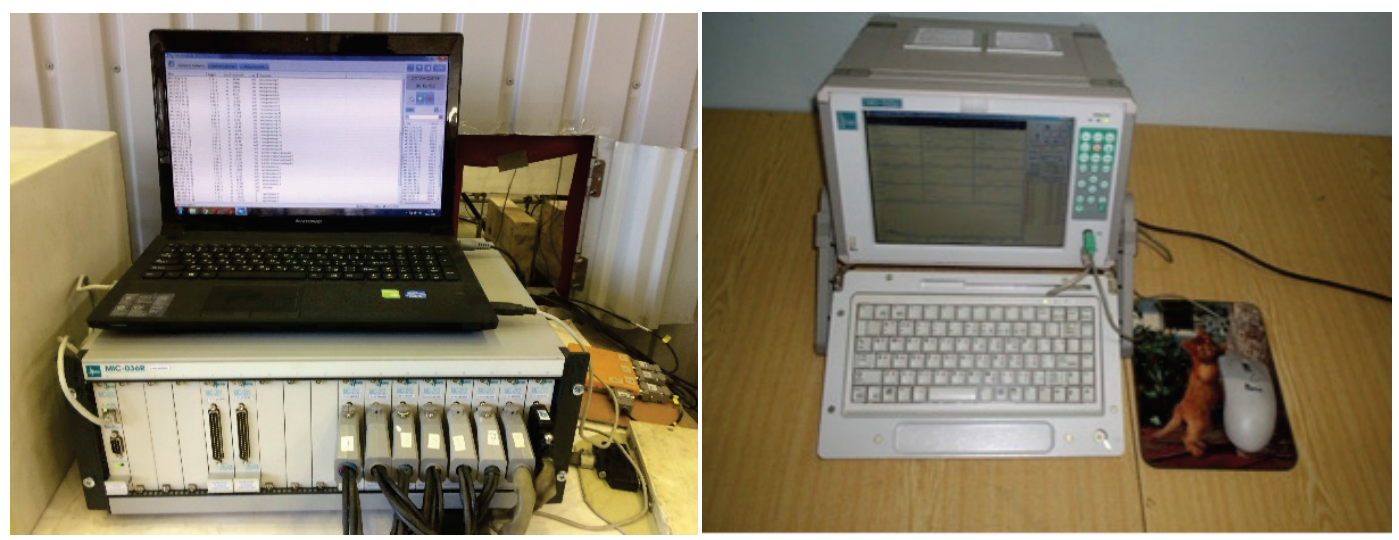

Puc. 5. Измерительно-вычислительные комплексы MIC-036R, MIC-300М

Fig. 5. Measuring-computing complexes MIC-036R, MIC-300M
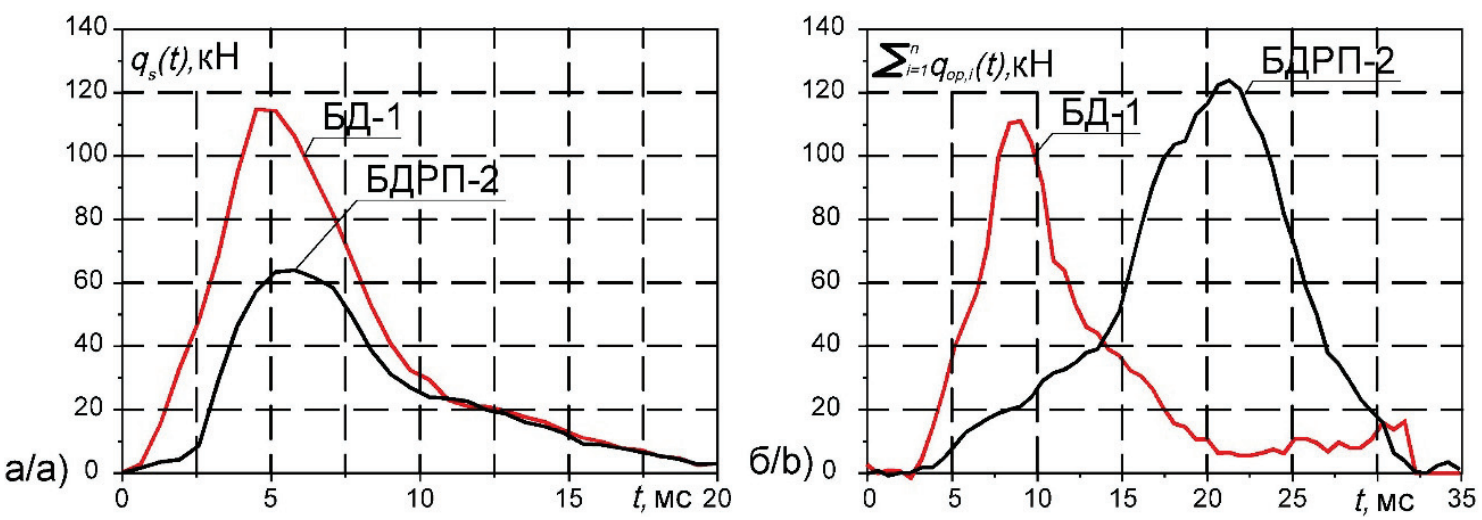

Puс. 6. Изленение входного (а) и выходного (б) силового воздействия во врелени для образцов БД-1, БДРП-2

Fig. 6. Change in input (a) and output (b) force effects in time for the samples BD-1, BDTF-2

следующей их обработкой. С целью сопоставления результатов испытаний образцов серии БД-1 и БДРП-2 построены диаграммы: изменение входного силового воздействия во времени (рис. $6, a)$, изменение выходного силового воздействия во времени (рис. 6, б), изменение перемещений во времени (рис. 7). На рис. 7 представлены две диаграммы, полученные в результате испытания соответствующих образцов БД-1 и БДРП- 2 , а также диаграмма БДРП-2, которая отражает перемещения конструкции без учета движения податливой опоры. Следует отметить, что для образца БД-1 диаграмма движения податливых опор отсутствует (в данном эксперименте податливые опоры не применяются).

В результате анализа полученных данных по перемещению (рис. 7) при интенсивном динамическом нагружении опытных образцов при равнозначных параметрах загружения (высота падения груза 0,75 м, масса груза составляла 450 кг) установлено, что использование податливых опор и учет реакции распора приводит к значительному снижению трещинообразования, тем самым обеспечивая живучесть испытуемых конструкций (рис. 7,8$)$, что подтверждается при раскадровке видеоряда с высокоскоростной камеры, на рис. 8 представлены фотографии при максимальном значении перемещений конструкций.

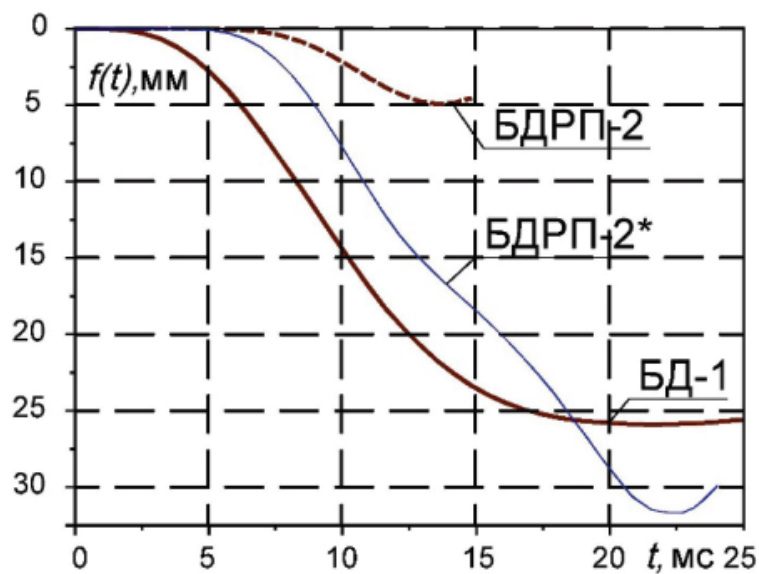

Puс.7. Изменение перемещений в середине пролета во времени для образиов БД-1, БДРП-2 (БДРП-2* - совместное перемещение конструкции и податливых опор)

Fig. 7. Time change of movements in the middle of the span for the samples BD-1, BDTF-2 (BDTF-2* - joint movement of the structure and yielding supports)

Анализ показаний перемещений во времени показывает, что наличие распора и использование податливых опор в образце БДРП-2 приводит к снижению прогибов конструкции в середине пролета в 5,4 раза относительно образца БД-1 (рис. 7). 
Снижение перемещений конструкции связанно с деформированием податливых опор, а также с увеличением продольной жесткости образца за счет включения в работу реакции распора в процессе интенсивного динамического нагружения.
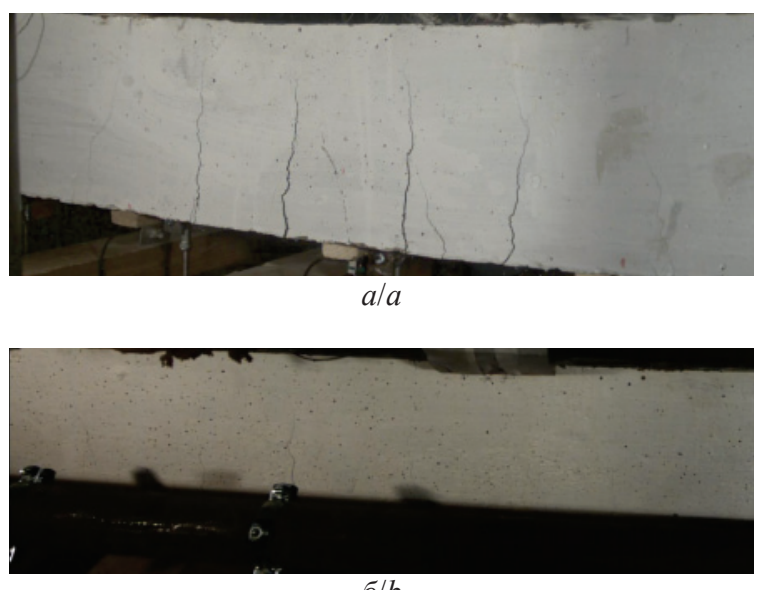

Puc. 8. Трещинообразование образиов БД-1 (а) и БДРП-2(б)

Fig. 8. Pattern of cracks development in samples BD-1 (a) and $B D T F-2(b)$

Оценив изменение входного силового воздействия во времени при кратковременном динамическом нагружении (рис. $6, a)$, можно сделать следующие выводы: наличие распора в образце БДРП2 приводит к снижению реакции системы на $44 \%$, причем время достижения максимального значения реакции несколько увеличилось за счет деформирования податливых опор; аналогично наблюдается увеличение времени достижения пиковых значений величины опорной реакций (рис. 6, б).

\section{Анализ параметров кратковременного}

\section{динамического нагружения}

Для оценки параметров кратковременного динамического нагружения использована методика, предложенная в работе [2]. С целью упрощения анализа напряженно-деформированного состояния временная шкала действия силы представлена в «мс», а шкала значений силы переведена в относительные единицы путем деления каждого показания всех датчиков на максимальную зафиксированную величину нагрузки:

$$
\begin{aligned}
q_{s, \max } & =114,7 \kappa \mathrm{H}(\text { БД-1); } \\
q_{s, \max } & =63,9 \kappa \mathrm{\kappa} \text { (БДРП-2). }
\end{aligned}
$$

Определение мгновенного значения коэффициента результирующей силы ${ }_{k}(t)$, приведенное на рис. 9 , производится путем нахождения разности между мгновенным значением силы (рис. $6, a)$ и суммарным мгновенным значением опорной реакции (рис. 6, б), деленной на максимальное значение силы для соответствующей серии испытаний:

$$
k(t)=\frac{q_{s}(t)-\sum_{i=1}^{n} q_{o p, i}(t)}{q_{s, \max }},
$$

где $k(t)$ - мгновенное значение коэффициента результирующей силы в строительной конструкции при ударном разрушении; $q_{s}(t)$ - мгновенное значения кратковременной динамической нагрузки при сверхнормативном ударном воздействии по показаниям силоизмерителя; $\sum_{i=1}^{n} q_{\text {op }, i}(t)$ - суммарное мгновенное значение опорной реакции; $q_{s, \max }-$ максимальное значение динамической нагрузки приложенного сверхнормативного ударного воздействия по показаниям силоизмерителя.

Физический смысл формулы (1) заключается в определении вертикальной составляющей испытательной нагрузки в функции времени, приложенной $к$ испытуемой строительной конструкции и выраженной в относительных единицах (рис. 9).

Определение усредненного значения коэффициента результирующей силы производится по следующей зависимости:

$$
k=\frac{\int_{t_{1}}^{t_{2}} q_{s}(t)-\sum_{i=1}^{n} \int_{t_{1}}^{t_{2}} q_{o p j}(t)}{\int_{t_{1}}^{t_{2}} q_{s}(t)},
$$

где $k$ - усредненное значение коэффициента результирующей силы в строительной конструкции при ударном разрушении на интервале времени $t_{1}-t_{2} ; t_{1}, t_{2}-$ метки времени начала и окончания ударного воздействия.

Значения мгновенного коэффициента результирующей силы (1) для образца БД-1 изменяются в пределах от $+0,77$ до -0,63; для образца БДРП-2 в пределах от $+0,86$ до $-1,9$ (рис. 9). При этом знак»+» характеризует превышение входной нагрузки над опорной реакцией, а знак «-» наоборот.

Усредненное значение коэффициента результирующей силы определяется по зависимости (2). Для образцов БД-1, БДРП-2 они равны соответственно $k_{\text {Бд }}=0,089 ; k_{\text {вдрп }}=0,72$. Усредненный коэффициент результирующей силы отражает долю энергии, затраченной на деформирование материала и выделение тепла в процессе испытания строительной конструкции на кратковременную динамическую сверхнормативную нагрузку. Таким образом, получен коэффициент увеличения затраченной энергии на деформирование образца БДРП-2 по отношению $к$ образцу БД-1: $k_{E}=\frac{k_{\text {БдРп }}}{k_{\text {Бд }}}=\frac{0,72}{0,089}=8,08$, и его физический смысл заключается в том, что в 8,08 раза снижена сила, которая могла пойти на разрушение образца, но которая аккумулируется в податливой опоре, выполняющей роль защитного элемента и защищающей строительную конструкцию.

Рассмотрим вычисление сил инерции, полученных по результатам испытаний образца БД-1 с акселерометрами, расположенными по длине конструкции с шагом 300 мм. Для вычисления сил инерции во времени просуммируем произведения 


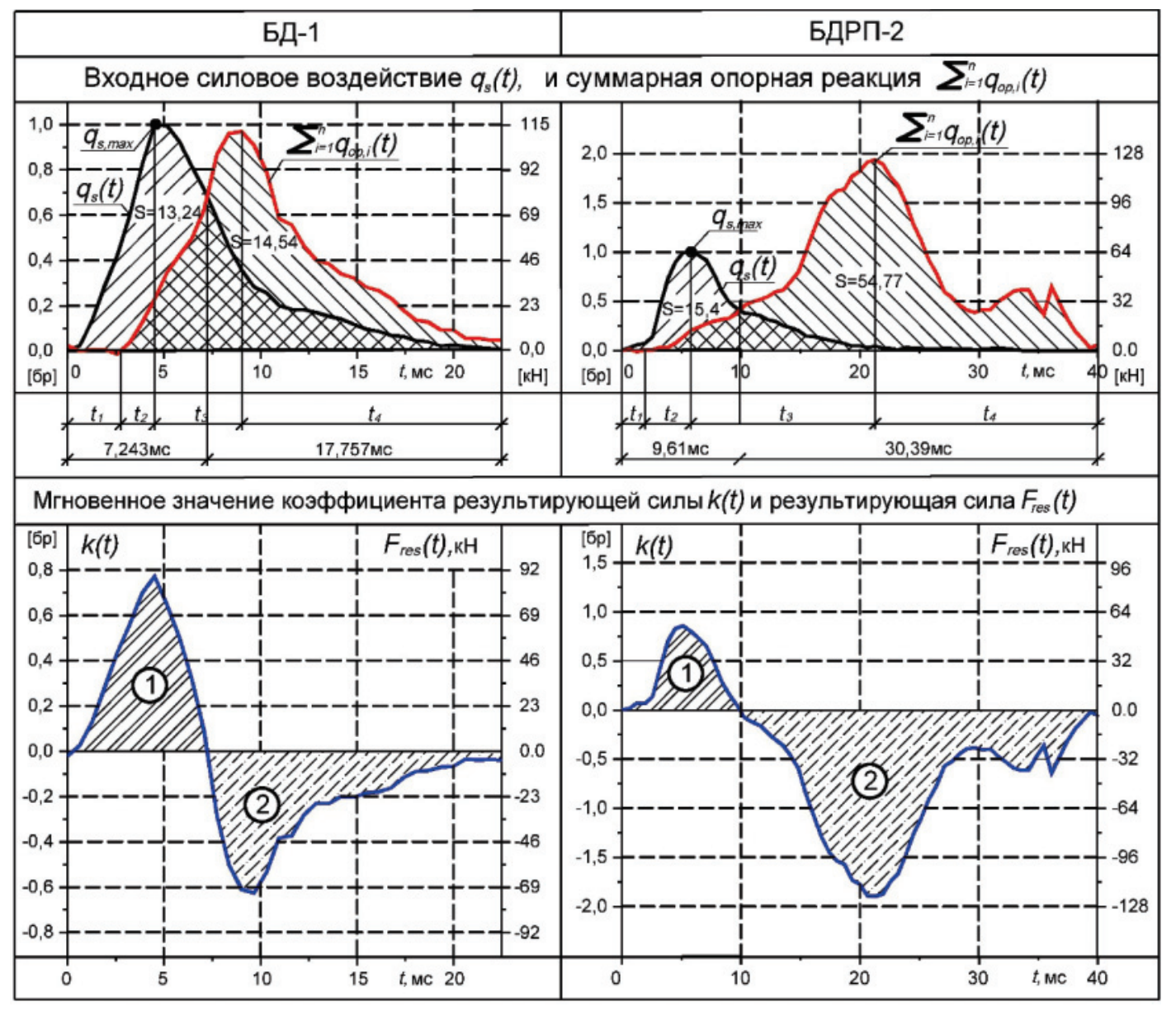

Рис. 9. Графики зависимости относительных и абсолютных значений входного силового воздействия и суммарной опорной реакиии от времени, а также графики изменения мгновенных значений коэффициента результирующей силы $k(t)$ и результирующей силь $F_{\text {res }}(t)$ в процессе испытания образиов БД-1 и БДРП-2. Обозначения: 1 - область превышения кратковременной динамической нагрузки; 2 - область превышения опорной реакиии системы

Fig. 9. Graphs of dependence of relative and absolute values of the input force action and the total reference reaction on time, as well as the graphs of instantaneous values of the resultant force $k(t)$ and the resultant force $F_{\text {res }}(t)$ during the testing of the BD-1 and BDTF-2 samples. Legend: 1 is the area of excess of short-term dynamic load; 2 is the area of exceeding the reference reaction of the system

показаний акселерометров на массу соответствующего участка конструкции (рис. 10):

$$
F_{I}(t)=\sum_{i=1}^{n} \int_{t_{1}}^{t_{2}} m_{i} \grave{a}_{i}(t),
$$

где $F_{I}(t)$ - сила инерции; $m_{i}$ - масса участка конструкции, соответствующей расположению акселерометров; $n$ - количество акселерометров; $a_{i}(t)-$ ускорения части конструкции, зафиксированные соответствующими акселерометрами.

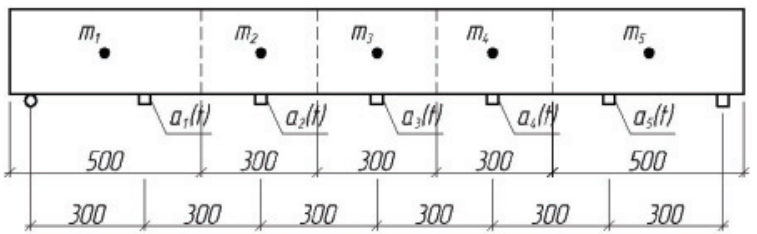

Рис. 10. Схема разграничения образиа с учетом расстановки акселерометров по длине

Fig. 10. Scheme of the sample demarcation taking into account the arrangement of accelerometers along the length
В результате можем вычислить по формуле (3) величину силы инерции балки на всем интервале действия нагрузки. Вычтем график распределения величины силы инерции во времени (график 2: черный цвет) на рис. 11 из графика входного силового воздействия (график 1: зеленый цвет) для образца серии БД-1. На рис. 11 представлена диаграмма деформирования арматуры 3 (синий цвет).

График 4 (фиолетовый цвет) характеризует развитие сил, связанных с деформированием образца $F_{\text {def }}(t)$, получен путем вычитания графиков 1 и 2.

Как видно из полученных диаграмм (рис. 11), на первом временном интервале $t_{0}=0 \mathrm{mc}$ до $t_{1}=2,68$ мс абсолютные значения разности между мгновенными показаниями силоизмерителя (график 1) совпадают с силами инерции, полученными экспериментально (график 2), что свидетельствует об упругой работе в ходе ударно-волнового нагружения и согласуется с упругими деформациями в рабочей арматуре в середине пролета (график 3 ) на рассматриваемом интервале. Дальнейшее расхож- 
дение графиков (заштрихованная область) отражает затраты силового воздействия на деформирование конструкции в пластической стадии, временной интервал от $t_{1}=2,68$ мс до $t_{2}=18,81$ мс. Таким образом, по зависимости (4) можно разграничить стадии деформирования конструкции на временном отрезке силового воздействия, а также количественно оценить величину ударно-волнового нагружения, направленного на деформирование образца:

$$
F_{\text {def }}(t)=q_{s}(t)-F_{I}(t)=q_{s}(t)-\sum_{i=1}^{n} \int_{t_{1}}^{t_{2}} m_{i} q_{i}(t) .
$$
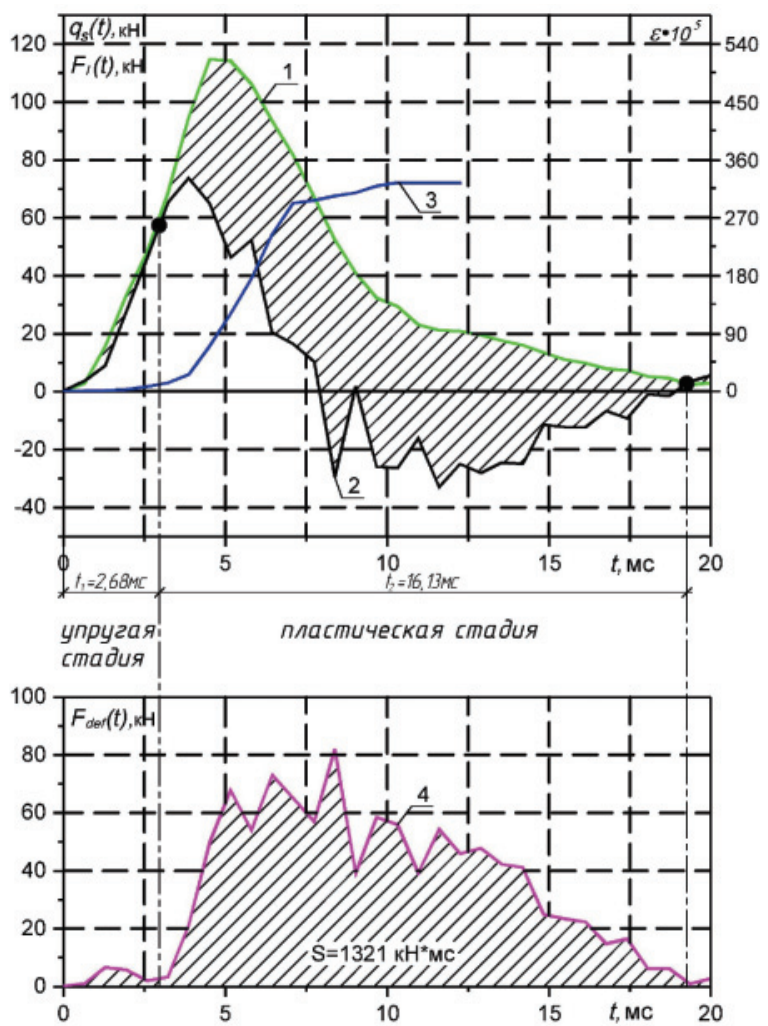

Рис.11. Графики зависимости входного силового воздействия $q_{s}(t)$ для образиа серии БД-1 (график 1) и распределения сил инериии $F_{I}(t)$ системы (график 2 ); диаграмма деформирования рабочей арматуры в середине пролета конструкиии (график 3); диаграмма развития усилий, связанных с деформированием образиа $F_{\text {def }}(t)$ (график 4$)$

Fig. 11. Graphs of dependence of the input force action $q_{s}(t)$ for the sample of the BD-1 series (graph 1) and distribution of the inertia forces $F_{I}(t)$ of the system (graph 2 ); diagram of deformation of the working reinforcement in the middle of the span of the structure (graph 3); diagram of development of forces associated with sample deformation $F_{\text {def }}(t)$ (graph 4$)$

Аналогично образцу БД-1 на рис. 11 построены графики для образца серии БДРП-2 (рис. 12). Необходимо отметить, что при вычислении сил инерции не учитывалась погрешность распределения масс, связанных с наличием ограничительного контура, вызывающего реакцию распора, за счет возможности поворота в шарнирном сопряжении торца балки с обеих сторон.
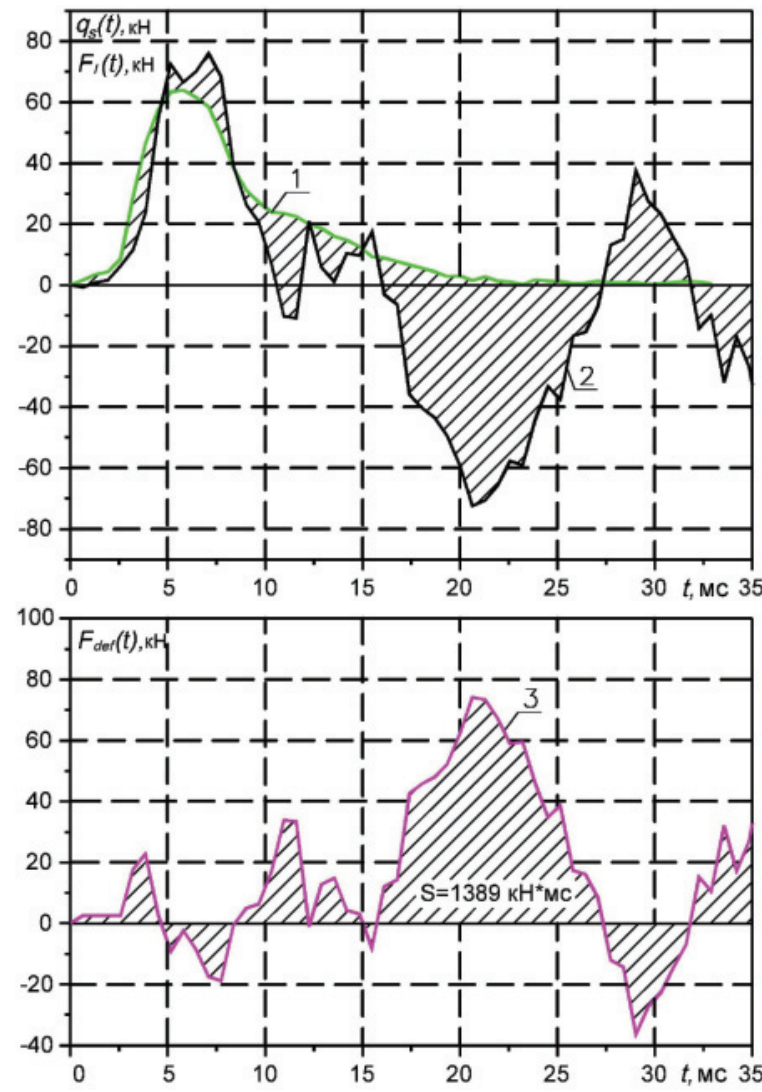

Рис. 12. Графики зависилости входного силового воздействия $q_{s}(t)$ для образиа серии БДРП-2 (график 1) и распределения сил инериии $F_{I}(t)$ систелы (график 2); диаграмла развития усилий, связанных с деформированием образиа $F_{\text {def }}(t)($ график 3$)$

Fig. 12. Graphs of dependence of the input force action $q_{s}(t)$ for a sample of the BDTF-2 series (graph 1) and distribution of the inertia forces $F_{I}(t)$ of the system (graph 2 ); diagram of development of forces associated with deformation of the sample $F_{\text {def }}(t)$ (graph 3$)$

Сравним график 4 рис. 11 с графиком 3 рис. 12. В результате сравнения можно вычислить коэффициент разброса силового воздействия $k_{F_{d e f}}$, отражающий отклонение импульса сил, связанных с деформированием образца БДРП-2 относительно БД-1 при равных параметрах ударно-волнового нагружения (высота падения груза 0,75 м, масса груза 450 кг). Для этого вычислим интеграл функций графика 4 рис. 11 и графика 3 рис. 12.

$$
\begin{gathered}
S_{\text {БД }}=\int_{t_{1}}^{t_{2}} F_{d e f}(t)=1321 \kappa \mathrm{H} \cdot \mathrm{Mc} ; \\
S_{\text {БДРП }}=\int_{t_{1}}^{t_{2}} F_{d e f}(t)=1389 \kappa \mathrm{H} \cdot \mathrm{Mc} ; \\
k_{F_{\text {def }}}=\frac{S_{\text {БДРП }}-S_{\text {БД }}}{S_{\text {БДРП }}} \cdot 100 \%=4,9 \% .
\end{gathered}
$$

Физический смысл коэффициента разброса силового воздействия $k_{F_{d e f}}$ заключается в отклонении импульса силы, приложенной к образцу, защищённому податливой опорой (БДРП-2), по отношению к 
образцу БД-1 без соответствующей защиты, при равных параметрах ударного нагружения (падения груза 750 мм, масса груза 450 кг), фактически это погрешность получения экспериментальных данных измерения, вызванная неидентичностью образцов в связи особенностями технологического процесса бетонирования и анизотропностью бетона.

Для сравнительного анализа процессов при ударно-волновом нагружении в конструкциях БД-1 (оранжевый цвет) и БДРП-2 (фиолетовый цвет) представлен спектральный состав на рис. 13. Амплитудные значения сигналов А по оси ординат приведены в относительных единицах [о.е.], полученных путем деления на максимальное значение амплитуды для образца БДРП-2. По оси абсцисс обозначена частота $v$ [Гц].

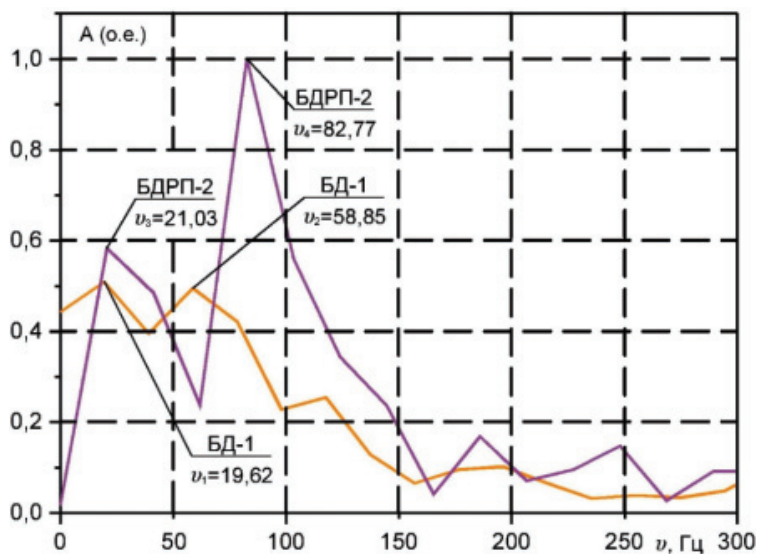

Pис. 13. Спектральный состав показаний акселерометра, распо ложенного в середине пролета для эксперилентальных образиов БД-1 и БДРП-2

Fig. 13. Spectral composition of the testimony of an accelerometer located in the middle of the span for experimental samples $B D-1$ and $B D T F-2$

a/a)

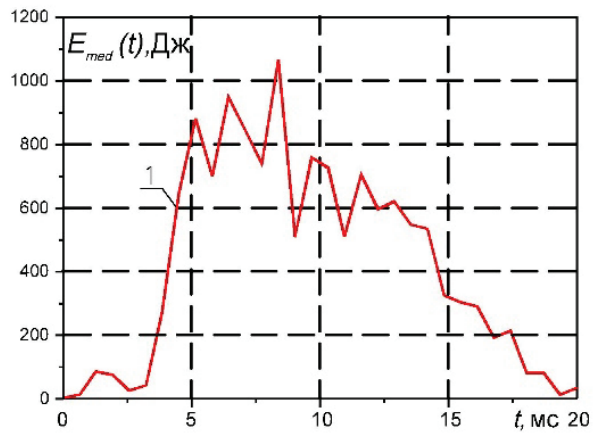

Как видно из рис. 13, для образца БД-1 можно наблюдать наличие нулевой гармоники колебаний конструкции, что хорошо согласуется с положительными значениями диаграммы развития усилий, связанных с деформированием образца $F_{\text {def }}(t)$ (рис. 11, график 4). Для образца БДРП-2 наблюдается колебательный процесс, что согласуется с рис. 12 , график 3 . На графиках рис. 13 можно наблюдать практическое совпадение пиков частот первых колебаний $v_{1}=19,62$ Гц и $v_{3}=21,03$ Гц, которые характеризуют частоту работы испытательного стендового оборудования, включающую в состав конструкцию, подвергнутую ударно-волновому нагружению. Вторые пики спектрального состава $v_{2}=58,85$ Гц и $v_{4}=82,77$ Гц связаны с колебаниями непосредственно первой гармоники испытуемой конструкции. Их различие свидетельствует об итоговом снижении несущей способности конструкции во время испытания для образца БД-1 без податливых опор относительно образца БДРП-2.

Для получения усредненной энергии деформирования на интервале действия нагрузки умножим $F_{\text {def }}(t)$ на усредненные перемещения конструкции по длине элемента:

$$
E_{\text {med }}(t)=F_{\text {def }}(t) f_{\text {med }}(t)
$$

где $E_{\text {mеd }}(t)$ - усредненная энергия деформирования на интервале действия нагрузки; $F_{\text {def }}(t)$ - сила, затраченная на деформирование образца; $f_{\text {med }}(t)$ - усредненные перемещения образца по длине на интервале действия сверхнормативного силового воздействия (среднее значение перемещений во времени по длине образца).

По представленной выше зависимости (5) построены усредненные энергетические диаграммы для образцов серии БД-1 и БДРП-2. б/b)

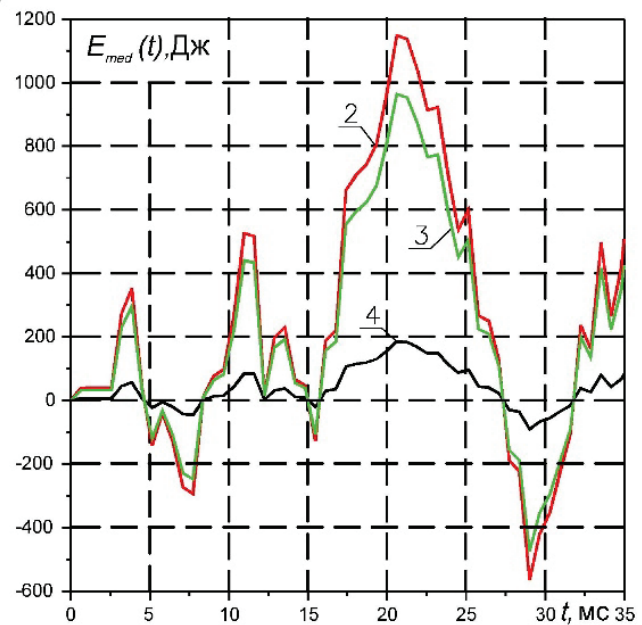

Рис. 14. Диаграмла усредненной энергии дефорлирования во времени для образцов серии БД-1 (а, график 1) и БДРП-2 (б, график 2 ); диаграмла усредненной энергии дефорлирования податливой опоры во врелени для образиа БДРП-2 (б, график 3); диагралма усредненной энергии дефорлирования образиа без учета смятия податливой опоры во времени для образиа БДРП-2 (б, график 4)

Fig. 14. Diagram of averaged deformation energy in time for samples of series BD-1 (a, graph 1) and BDTF-2 (b, graph 2$)$; diagram of the averaged deformation energy of the yielding support in time for the sample BDTF-2 (b, graph 3); diagram of the average deformation energy of the sample without taking into account the crushing of the yielding support in time for the sample BDTF-2 (b, graph 4$)$ 


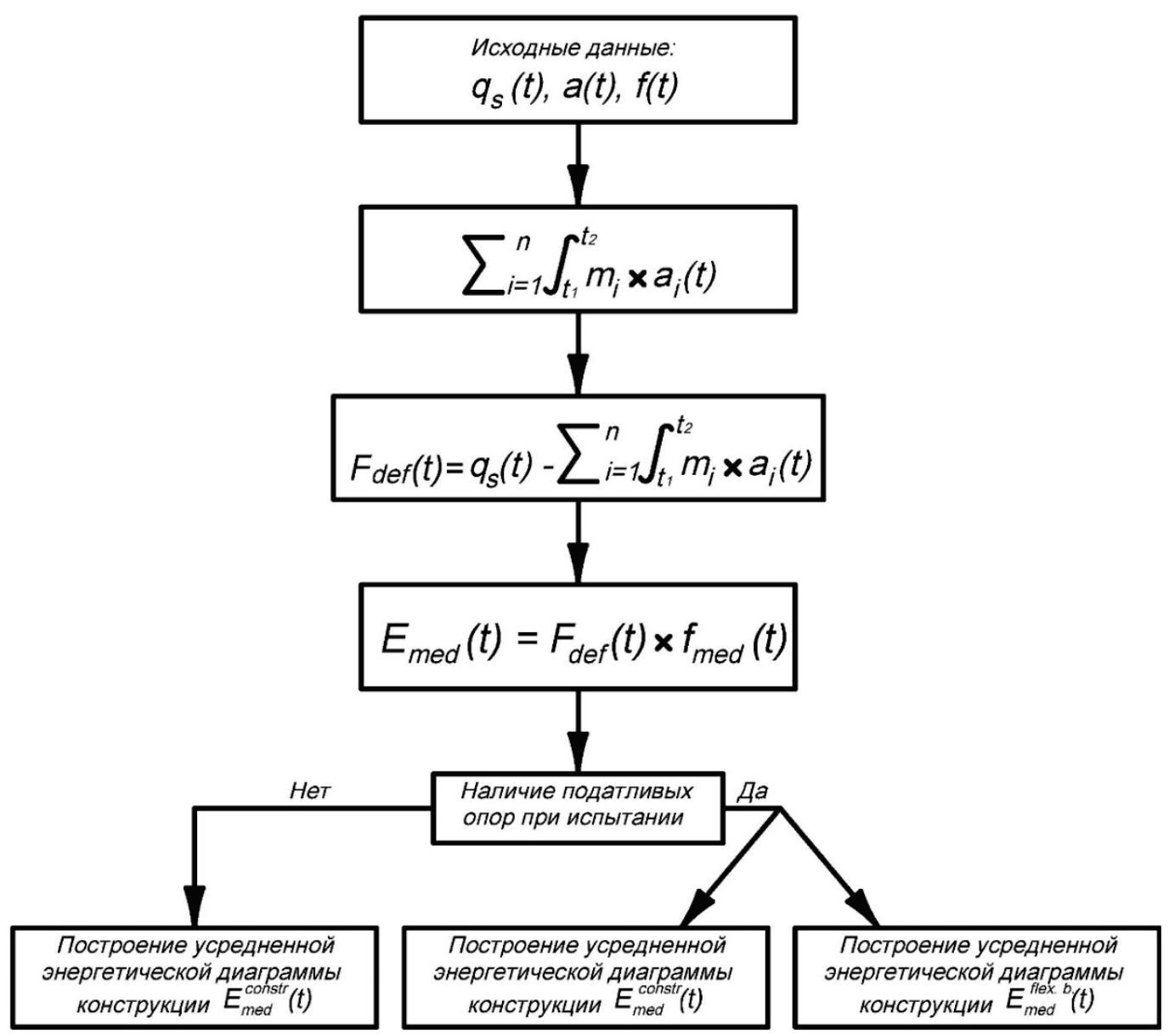

Рис. 15. Блок-схема алгоритла для построения энергетической диаграмлы для балок без податливых опор (Бд-1), а также при их наличии (БДРП-2)

Fig. 15. Block diagram of the algorithm for constructing energy diagram for beams without flexible bearing (BD-1), as well as in their presence (BDTF-2)

Из энергетических диаграмм (рис. 14) видно, что максимальное значение энергии $E_{\text {med }}^{\mathrm{EL}}=1050$ Дж для конструкции серии БД-1 и $E_{\text {med }}^{\text {Бाय }}=1150$ Дж для конструкции серии БДРП-2. Причем для образца БДРП-2 на рис. 13, б отражено перераспределение энергии, приходящейся на деформирование конструкции $E_{m e d, c}^{\text {БДРП }}=195$ Дж, и энергии, приходящейся на деформирование податливой опоры $E_{\text {med.f }}^{\text {Бाрп }}=950$ Дж. Таким образом, увеличение значений энергий, затраченных на деформирование балки, можно охарактеризовать энергетическим коэффициентом

$$
k_{E, \text { med }}=\frac{E_{\text {med }}^{\text {БД }}}{E_{\text {med,c }}^{\text {БДРП }}}=\frac{1050 \text { Дж }}{195 \text { Дж }}=5,38,
$$

физический смысл которого заключается в том, что энергия, приложенная к конструкции в испытании образца серии БДРП-2, сократилась в 5,38 раз, за счет энергопоглощения податливой опорой, причем величина коэффициента энергоемкости податливой опоры составила

$$
k_{E, f l e x, b}=\frac{E_{\text {med, } f}^{\text {БДР }}}{E_{\text {med }}^{\text {EДРI }}}=\frac{950 \text { Дж }}{1150 \text { Дж }}=0,826 .
$$

На рис. 15 приведен разработанный алгоритм, представленный в виде блок-схемы для обработки экспериментальных данных железобетонных балок на податливых опорах с распором, в частности получение усредненной энергетической диаграммы, а также перераспределение энергии между конструкцией и податливыми опорами.

\section{Выводы}

1. Разработан алгоритм построения усредненной энергетической диаграммы на основе экспериментальных данных, и получены аналитические зависимости для оценки влияния податливости опор.

2. Предложена методика оценки применения податливой опоры в образце БДРП-2 по сравнению с образцом БД-1 без податливой опоры с помощью энергетического коэффициента $k_{E, m e d}=5,38$, иллюстрирующего снижение энергии, затраченной на деформирование конструкции, за счет перераспределения энергии между конструкцией и податливой опорой при равных параметрах ударного нагружения (высота падения груза 750 мм, масса груза 450 кг). 
3. Получена оценка энергоемкости использования податливой опоры при испытаниях серии БДРП-2, в результате установлено, что $82,6 \%$ энергии было поглощено за счет использования податливых опор.

4. Получен коэффициент разброса силового воздействия $k_{F_{d e f}}=4,9 \%$, который характеризует отклонение интегрального значения силы, приложенной $\mathrm{\kappa}$ образцу, защищённому податливой опорой (БДРП-2), по отношению к образцу БД-1 без соответствующей защиты, при равных параметрах ударного нагружения (падения груза 0,75 м, масса груза 450 кг), это позволяет оценить погрешность, связанную с неидентичностью образцов и анизатропностью бетона.

\section{СПИСОК ЛИТЕРАТУРЫ}

1. Аварии и катастрофы. Предупреждение и ликвидация последствий. Кн. 4 / В.А. Котляревский, А.В. Забегаев, Ю.Н. Глазунов, А.А. Петров / под ред. В.А. Котляревского, А.В. Забегаева. - М.: Изд-во АСВ, 1998. - 204 с.

2. Бирбраер А.Н., Роледер А.Ю. Экстремальные воздействия на сооружения. - СПб.: Изд-во Политехнического университета, 2009. $-594 \mathrm{c}$.

3. Тамразян А.Г. Оценка живучести зданий при комбинирован ных аварийных воздействиях // Безопасность жизнедеятельности. - 2003. - № 10. - С. 39-41.

4. Тонких Г.П. По вопросу использования динамических испытаний для оценки технического состояния и сейсмостойкости зданий и сооружений // Мониторинг. Наука и безопасность. 2012. - № 4 (8). - C. 54-58.

5. Pakhmurin 0.R. Prevention of uncontrolled progressive collapse of a high-rise brick building // Youth, Science, Solutions: Ideas and Prospects: IV International Young Researchers Conference. Tomsk, 2017. - V. 143. $-6 \mathrm{p}$.

6. Балдин И.В. Исследование железобетонных коротких цилиндрических оболочек покрытий при кратковременном динамическом нагружении: дис. ... канд. техн. наук. - Томск, 1994. 334 c.

7. Н.Н. Белов, Н.Т. Югов, Д.Г. Копаница, В.С. Плевков, А.А. Югов, В.В. Шашков, К.Л. Кудяков, А.М. Устинов. Модель динамического разрушения фибробетона // Вестник Томского государственного архитектурно-строительного университета. - 2014. - № 5 (46). - С. 63-76.

8. Педиков А.В. Исследование сжато-изгибаемых железобетонных балочных конструкций на податливых опорах при кратковременном динамическом нагружении: дис. ... канд. техн. наук. - Томск, 2006. - $174 \mathrm{c.}$

9. Плевков В.С., Колупаева С.Н., Кудяков К.Л. Расчетные диаграммы нелинейного деформирования базальтофибробетона при статических и кратковременных динамических воздействиях // Вестник Томского государственного архитектурностроительного университета. - 2016. - № 3 (56). - С. 95-110.

10. Плевков В.С., Балдин И.В., Кудяков К.Л., Невский А.В. Прочность и деформативность арматуры композитной полимерной при статическом и кратковременном динамическом растяжении и сжатии // Вестник Томского государственного архитектурно-строительного университета. - 2016. - № 5 (58). C. $91-101$.

11. Родевич В.В., Арзамасцев С.А. К оценке прочности железобетонных изгибаемых элементов при кручении от кратковременных динамических нагрузок // Вестник Томского государственного архитектурно-строительного университета. 2017. - № 2. - C. 112-122.
5. Получены мгновенные значения и усредненное значение коэффициентов результирующей силы с применением податливой опоры в образце БДРП2 и без податливой опоры в образце БД-1, которые составили соответственно $k(t)=+0,77 \ldots-0,63$, $k=0,089$ - для балки серии БД- $1 ; k(t)=+0,86 . . .-1,9$, $k=0,72$ - для балки серии БДРП-2.

6. Получен коэффициент увеличения затраченной энергии на деформирование образца БДРП-2 по отношению к образцу БД-1: $k_{E}=\frac{k_{\text {БдРп }}}{k_{\text {Бд }}}=8,08$, причем сила, которая могла пойти на разрушение образца, аккумулируется в податливой опоре, выполняющей роль защитного элемента.

12. Саргсян А.Е. Динамика и сейсмостойкость сооружений атомных станций. - Саров: ФГУП «РФЯЦ-ВНИИЭФ», 2013. $550 \mathrm{c.}$

13. СП 88.13330.2014. Защитные сооружения гражданской обороны. Актуализированная редакция. - М.: НИИЖБ им Гвоздева A.A., 2014. - 156 c.

14. Study of deformations evolution in near-surface layers of adhesive joints / A. Ustinov, D. Kopanitsa, Yu. Abzaev, A. Klopotov, B. Koshko, G. Kopanitsa // $3^{\text {rd }}$ International Young Researchers Conference on Youth, Science, Solutions: Ideas and Prospects. Tomsk, 2018. - V. 1800 - 7 p. DOI: $10.1063 / 1.4973048$

15. Strength calculation for fiber concrete slabs under high velocity impact / A. Ustinov, D. Kopanitsa, N. Belov, N. Yugov, A. Yugov, B. Koshko, G. Kopanitsa // $3^{\text {rd }}$ International Young Researchers Conference on Youth, Science, Solutions: Ideas and Prospects. - Tomsk, 2018. - V. 1800. - 6 p. D0I: $10.1063 / 1.4973049$

16. Kudyakov K.L., Plevkov V.S., Nevsky A.V. Strength and deformability of concrete beams reinforced by non-metallic fiber and composite rebar // IOP Conf. Series: Materials Science and Engineering. -2015 . - V. 71. - P. 2-7.

17. Experimental and numerical investigation of concrete structures with metal and non-metal reinforcement at impulse loadings / P.A. Radchenko, S.P. Batuev, A.V. Radchenko, V.S. Plevkov, K.L. Kudyakov // IOP Conf. Series: Journal of Physics. - 2016. V. 774 . - P. 2-8.

18. Mechanical properties of composite rebar under static and shortterm dynamic loading / V.S. Plevkov, I.V. Baldin, K.L. Kudyakov, A.V. Nevskii // AIP Conference Proceedings. - Tomsk, 2017. - V. 1800. - 2-6 pp. DOI: $10.1063 / 1.4973059$

19. Стекольников Ю.И. Живучесть систем. - СПб.: Политехника, 2002. $-155 \mathrm{c}$.

20. Odnokopylov G.I., Bragin A.D. Fault tolerant vector control of induction motor drive // IOP Conference Series: Materials Science and Engineering. - 2014. - V. 66. - № 1. - P. 1-6. - Article number 012015

21. Odnokopylov G.I., Rozaev I.A. Formation of failure matrix and failure-free control algorithm for multi-sectioned Switched-reluctance drive // IOP Conference Series: Materials Science and Engineering. - 2014. - V. 66. - № 1. - P. 1-7. - Article number 012035 .

22. Odnokopylov G.I., Bragin A.D. Mathematical model of brushless DC motor in phase loss operation mode // Applied Mechanics and Materials. - 2015. - V. 698. - P. 24-29.

23. Odnokopylov G.I., Bragin A.D. Algorithms of fault tolerant control of induction motor electric drive in phase loss operate mode // 2015 International Siberian Conference on Control and Communications (SIBCON): Proc. - Omsk, May 21-23, 2015. - Novosibirsk: IEEE Russia Siberia Section, 2015 - P. 1-5. 
24. Odnokopylov G.I., Rozaev I.A. Fault-tolerant control of switched-reluctance drive in emergency modes // 2015 International Siberian Conference on Control and Communications (SIBCON): Proc. - Omsk, May 21-23, 2015. - Novosibirsk: IEEE Russia Siberia Section, 2015. - P. 140-144.

25. Odnokopylov G.I., Rozaev I.A. Fault-tolerant control algorithms of switched-reluctance motor drive in open-phase modes // 2016 The $11^{\text {th }}$ International Forum on Strategic Technology (IFOST): Proc. - Novosibirsk, June 1-3, 2016. - Novosibirsk: IEEE Russia Siberia Section, 2016. - P. 140-144.

26. Influence of Design Methods a Discrete Model of Separately Excited DC Motor on Parameters Estimation / I. Vajda, A. Glazyrin, I. Ustinova, E. Bolovin // Acta Polytechnica Hungarica. 2018. - V. 15. - № 6. - P. 219-233.

27. Резонансные колебания с предельной амплитудой в вибрационом электромагнитном активаторе / А.Н. Гварилин, Е.В. Боловин, А.С. Глазырин, С.Н. Кладиев, В.И. Полищук // Известия Томского политехнического университета. Инжиниринг георесурсов. - 2019. - Т. 330. - № 1. - C. 201-213. DOI: $10.18799 / 24131830 / 2019 / 1 / 70$

28. Особенности разрушения железобетонных конструкций при динамическом нагружении / В.С. Плевков, А.В. Радченко, И.В. Балдин, П.А. Радченко, М.Е. Гончаров, С.П. Батуев // Вестник Тамбовского Университета. - 2013. - Т. 18. Вып. 4. - С. 1578-1579.

29. Tensile behavior of concrete under high loading rates / J. Ozbolt, A. Sharma, B. Irhan, E. Sola // Int. J. of Impact Eng. - 2014. V. 69. - № 5. - P. 55-68.

30. Strain rate dependent tensile behavior of advanced high strength steels / J.H. Kim, D. Kim, Han Heung Nam et al. // Materials Science \& Engineering A. - 2013. - № 559. - P. 222-231.

31. Shang S., Song Y. Dynamic biaxial tensile-compressive strength and failure criterion of plain concrete // Construction and Building Materials. - 2013. - V. 40. - № 2. - P. 322-329.

32. Однокопылов Г.И., Саркисов Д. Ю. Оценка параметров разрушающей нагрузки при ударно-волновом нагружении для ответственных строительных конструкций сооружений нефтегазового комплекса // Известия Томского политехнического университета. Инжиниринг георесурсов. - 2017. - Т. 328. № 3. - C. $85-95$.

33. Попов Н.Н., Расторгуев Б.С. Вопросы расчета и конструирования специальных сооружений. - М.: Стройиздат, 1980. $190 \mathrm{c.}$

34. Попов Н.Н., Расторгуев Б.С., Забегаев А.В Расчет конструкций на динамические специальные нагрузки. - М.: Высшая школа, 1992. - 319 c.

35. Расторгуев Б.С. Обеспечение живучести зданий при особых динамических воздействиях // Сейсмостойкое строительство. Безопасность сооружений. - 2003. - № 4. - С. 45-48.

36. Расторгуев Б.С. Применение динамических гасителей колебаний при взрывных воздействиях // Строительная механика и расчет сооружений. - 2009. - № 1. - С. 50-57.

37. Виноградова Т.Н. Влияние распора на работу железобетонных балочных конструкций при кратковременных динамических воздействиях: дис. ... канд. техн. наук. - М., 1977. - 155 с.

38. Зулпуев А.М. Исследование напряженно-деформированного состояния железобетонных распорных плит перекрытий в зданиях с монолитными стенами: монография. - Бишкек: Илим,
2010. -80 c.

39. Зулпуев А.М., Бактыгулов К. Расчет на прочность сборных железобетонных плит перекрытий, опертых по контуру // Территория науки. - 2016. - Т. 1. - С. 63-68.

40. Тихонов И.Н. Принципы расчета прочности и конструирования армирования балок перекрытий зданий из монолитного железобетона для предотвращения прогрессирующего разрушения // Научно-технический и производственный журнал «Жилищное строительство». - 2013. - № 2. - С. 40-45.

41. Тихонов И.Н. Армирование железобетонных конструкций зданий, проектируемых с учетом воздействия особых нагрузок: дис. ... д-ра техн. наук. - М., 2015. - 337 с.

42. High strength and reactive powder concrete columns subjected to impact: Experimental investigation / L. Huynh, S. Foster, H. Valipour, R. Rendall // Construction and Building Materials. 2015. - V. 78. - P. 153-171.

43. Kumpyak 0.G., Galyautdinov Z.R., Galyautdinov D.R. Experimental study of beams on yielding supports with thrust // Youth, Science, Solutions: Ideas and Prospects: IV International Young Researchers Conference. - Tomsk, 2017. - V. 143. - 6 p.

44. Саид А.Р.А. Повышение несущей способности железобетонных конструкций при взрывных воздействиях: дис. ... канд. техн. наук. - М., 1995. - 207 c.

45. Попов Н.Н., Расторгуев Б.С. Расчет железобетонных конструкций на действие кратковременных динамических нагрузок. - М.: Стройиздат, 1964. - 151 с.

46. 3D Modelling of reinforced concrete slab with yielding supports subject to impact load / A. Kezmani, L. Placidi, B. Chiaia, 0. Kumpyak, V. Maksimov // European Journal of Environmental and Civil Engineering. - 2016. - V. 21. - P. 1-38. DOI: 10.1080/19648189.2016.1194330

47. Kumpyak 0.G., Galyautdinov Z.R., Kokorin D.N. Strength of concrete structures under dynamic loading // AIP Conference Proc. Advanced Materials in Technology and Construction. Tomsk, 2016. - P. 59-68.

48. Elfetori F.A. Experimental Testing of Composite Tubes with Different Corrugation Profile Subjected to Lateral Compression Load // Engineering and Technology International Journal of Mechanical, Industrial Science and Engineering. - 2013. - V. 7. - № 2. P. 10-15.

49. Fan Z., Shen J., Lu G. Investigation of Lateral Crushing of Sandwich Tubes // The Twelfth East Asia-Pacific Conference on Structural Engineering and Construction Procedia Engineering. - Hong Kong, 2011. - № 14. - P. 442-449.

50. Impact Energy Absorption of Concentric Circular Tubes / K.H. Lion, R.A.G. Amir, E. Prasetyo, Y. Khairi // WSEAS Transactions on Aapplied and Theoretical Mechanics. - 2009.- V. 4. № 3. - P. 95-104.

51. Lipa S., Kotelko M. Lateral impact of tubular structure - theoretical and experimental analysis. P. 1 - Investigation of single tube // Journal of theoretical and applied mechanics. $-2013 .-$ V. 51. № 4. - P. 873-882.

52. Somya P., Chawalit T., Umphisak T. An Analysis of Collapse Mechanism of Thin-Walled Circular Tubes Subjected to Bending // Proc. of World Academy of Science: Engineering \& Technology. Dec. 2007. - V. 36. - P. 329-334.

Поступила 28.02.2019 г. 


\section{Информация об авторах}

Однокопылов Г.И., доктор технических наук, доцент отделения электроэнергетики и электротехники Национального исследовательского Томского политехнического университета.

Кумпяк O.Г., доктор технических наук, профессор кафедры железобетонных и каменных конструкций Томского государственного архитектурно-строительного университета.

Галяутдинов 3.P., кандидат технических наук, доцент кафедры железобетонных и каменных конструкций Томского государственного архитектурно-строительного университета.

Галяутдинов Д.P., аспирант кафедры железобетонных и каменных конструкции Томского государственного архитектурно-строительного университета. 


\title{
DETERMINATION OF VITALITY PARAMETERS OF PROTECTED CRITICAL ENGINEERING STRUCTURES UNDER SHOCK-WAVE LOADING
}

\author{
Georgy I. Odnokopylov', \\ OGIz@yandex.ru \\ Oleg G. Kumpyak², \\ OGKumpyak@yandex.ru \\ Zaur R. Galyautdinov ${ }^{2}$, \\ GaZR@yandex.ru \\ Daud R. Galyautdinov², \\ DaudG@yandex.ru \\ 1 National Research Tomsk Polytechnic University, \\ 30, Lenin Avenue, Tomsk, 634050, Russia. \\ 2 Tomsk State University of Architecture and Building, \\ 2, Solyanaya Square, Tomsk, 634003, Russia.
}

The relevance of work is related to the trend of emergencies at oil and gas industry enterprises. In this relation, it is necessary to de-
sign reinforced concrete structures, which can be affected by intensive short-term dynamic loads of emergency shock-wave type. Ta-
king into account the reaction of expansion during design allows revealing the hidden reserves of load-bearing capacity in bent ferro-
concrete structures, as well as reducing cracking, due to the increase in rigidity. The effective way to reduce the magnitude of the dyna-
mic impact is the use of yielding supports in the form of collapsible inserts of the annular section. Thus, the joint application of yielding
supports and consideration of the spacer reaction make it possible to prevent damage, complete or partial destruction of structures. In
addition, damage to the building structures of critical buildings and structures of the oil and gas complex leads to a halt in technological
process, which in some cases is not only economically unprofitable, but also unacceptable, and can lead to significant material damage
and loss of life.
The aim of the work is to develop a methodology and algorithm for constructing energy diagram, perform a numerical assessment of using compliant supports for survivability of protected building structures under intensive loading

Methods: experimental studies: reaction of input force, reaction of output force, acceleration, displacement by tensometry methods, numerical integration by Simpson method.

Results. The authors have developed the technique and algorithm for constructing the averaged energy diagram and carried out the numerical assessment of using malleable supports for survivability of protected building structures of oil and gas facilities under short-term dynamic loading.

\section{Key words:}

Vitality, protected building construction, energy diagram, coefficient of resultant force, short-term dynamic loading, shock-wave loading, reinforced concrete, thrust, flexible supports, inertial forces, experimental studies.

\section{REFERENCES}

1. Kotlyarevskiy V.A., Zabegaev A.V., Glazunov Yu.N., Petrov A.A. Avarii i katastrofy. Preduprezhdenie i likvidatsiya posledstviy [Accidents and disasters. Prevention and elimination of consequences]. Eds. V.A. Kotlyarevsky, A.V. Zabegayev. Moscow, ASV Publ., 1998. B. 4, 204 p.

2. Birbrayer A.N., Roleder A.Yu. Ekstremalnyye vozdeystviya na sooruzheniya [Extreme Impacts on Structures]. St-Peterburg, Polytechnic University Publ., 2009. 594 p.

3. Tamrazyan A.G. Otsenka zhivuchesti zdaniy pri kombinirovannykh avariynykh vozdeystviyakh [Assessment of survivability of buildings under combined emergency effects]. Bezopasnost zhiznedeyatelnosti, 2003, no. 10, pp. 39-41.

4. Tonkikh G.P. Po voprosu ispolzovaniya dinamicheskikh ispytaniy dlya otsenki tekhnicheskogo sostoyaniya i seysmostoykosti zdaniy i sooruzheniy [Issue of using dynamic tests to assess the technical state and seismic stability of buildings and structures]. Monitoring. Nauka i bezopasnost, 2012, no. 4 (8), pp. 54-58.

5. Pakhmurin 0.R. Prevention of uncontrolled progressive collapse of a high-rise brick building. IV International Young Researchers Conference. Youth, Science, Solutions: Ideas and Prospects. Tomsk, 2017. Vol. 143, 6 p.
6. Baldin I.V. Issledovanie zhelezobetonnykh korotkikh tsilindricheskikh obolochek pokrytiy pri kratkouremennom dinamicheskom nagruzhenii. Dis. Kand. nauk [Investigation of reinforced concrete short cylindrical shells of coatings under short-term dynamic loading. Cand. Diss.]. Tomsk, 1994. 334 p.

7. Belov N.N., Yugov N.T., Kopanitsa D.G., Plevkov V.S., Yugov A.A., Shashkov V.V., Kudyakov K.L., Ustinov A.M. Model of dynamic destruction of fiber concrete. Vestnik of Tomsk State University of Architecture and Building, 2014, no. 5(46), pp. 63-76. In Rus.

8. Pedikov A.V. Issledovanie szhato-izgibayemykh zhelezobetonnykh balochnykh konstruktsiy na podatlivykh oporakh pri kratkouremennom dinamicheskom nagruzhenii. Dis. Kand. nauk [Investigation of compressible-bending reinforced concrete girder structures on compliant supports under short-term dynamic loading. Cand. Diss.]. Tomsk, 2006. 174 p.

9. Plevkov V.S., Kolupaeva S.N., Kudyakov K.L. Calculated diagrams of nonlinear deformation of basalt fiber concrete during static and short-term dynamic effects. Vestnik of Tomsk State University of Architecture and Building, 2016, no. 3 (56), pp. 95-110. In Rus.

10. Plevkov V.S., Baldin I.V., Kudyakov K.L., Nevskiy A.V. Strength and deformability of composite polymer reinforcement 
under static and short-term dynamic tension and compression. Vestnik of Tomsk State University of Architecture and Building, 2016, no. 5 (58), pp. 91-101. In Rus.

11. Rodevich V.V., Arzamastsev S.A. To evaluation of strength of reinforced concrete bending elements under torsion from shortterm dynamic loads. Vestnik of Tomsk State University of Architecture and Building, 2017, no. 2 (61), pp. 112-122. In Rus.

12. Sargsyan A.E. Dinamika i seysmostoykost sooruzheniy atomnykh stantsiy [Dynamics and seismic resistance of nuclear facilities]. Sarov, RFYaTs-VNIIEF Publ., 2013. 550 p.

13. SP 88.13330.2014. Zashchitnye sooruzheniya grazhdanskoy oborony [Civil defense defenses. Moscow, NIIZhB im. Gvozdeva A.A. Publ., 2014. $156 \mathrm{p}$.

14. Ustinov A., Kopanitsa D., Abzaev Yu., Klopotov A., Koshko B., Kopanitsa G. Study of deformations evolution in near-surface layers of adhesive joints. $3^{\text {rd }}$ International Young Researchers Conference on Youth, Science, Solutions: Ideas and Prospects. Tomsk, 2018. Vol. 1800,7 p. DOI: $10.1063 / 1.4973048$

15. Ustinov A., Kopanica D., Belov N., Yugov N., Ygov A., Koshko B., Kopanitsa G. Strength calculation for fiber concrete slabs under high velocity impact. $3^{\text {rd }}$ International Young Researchers Conference on Youth, Science, Solutions: Ideas and Prospects. Tomsk, 2018. Vol. 1800. - 6 p. DOI: $10.1063 / 1.4973049$

16. Kudyakov K.L., Plevkov V.S., Nevsky A.V. Strength and deformability of concrete beams reinforced by non-metallic fiber and composite rebar. IOP Conf. Series: Materials Science and Engineering, 2015, vol. 71, pp. 2-7.

17. Radchenko P.A., Batuev S.P., Radchenko A.V., Plevkov V.S., Kudyakov K.L. Experimental and numerical investigation of concrete structures with metal and non-metal reinforcement at impulse loadings. IOP Conf. Series: Journal of Physics, 2016, vol. 774, pp. 2-8.

18. Plevkov V.S., Baldin I.V., Kudyakov K.L., Nevskii A.V. Mechanical properties of composite rebar under static and short-term dynamic loading. AIP Conference Proceedings. Tomsk, 2017. Vol. 1800. pp. 2-6. DOI: 10.1063/1.4973059.

19. Stekolnikov Yu.I. Zhivuchest sistem [Survivability of systems]. St-Petersburg, Politekhnika Publ., 2002. 155 p.

20. Odnokopylov G.I., Bragin A.D. Fault tolerant vector control of induction motor drive. IOP Conference Series: Materials Science and Engineering, 2014, vol. 66, no. 1, pp. 1-6,. Article number 012015 .

21. Odnokopylov G.I., Rozaev I.A. Formation of failure matrix and failure-free control algorithm for multi-sectioned Switched-reluctance drive. IOP Conference Series: Materials Science and En gineering, 2014, vol. 66, no. 1, pp. 1-7, Article number 012035

22. Odnokopylov G.I., Bragin A.D. Mathematical model of brushless DC motor in phase loss operation mode. Applied Mechanics and Materials, 2015, vol. 698, pp. 24-29.

23. Odnokopylov G.I., Bragin A.D. Algorithms of fault tolerant control of induction motor electric drive in phase loss operate mode. International Siberian Conference on Control and Communications (SIBCON): proceedings. Omsk, May 21-23, 2015. Novosibirsk, IEEE Russia Siberia Section, 2015. pp. 1-5.

24. Odnokopylov G.I., Rozaev I.A. Fault-tolerant control of switched-reluctance drive in emergency modes. International Siberian Conference on Control and Communications (SIBCON): proceedings. Omsk, May 21-23, 2015. Novosibirsk, IEEE Russia Siberia Section, 2015. pp. 140-144.

25. Odnokopylov G.I., Rozaev I.A. Fault-tolerant control algorithms of switched-reluctance motor drive in open-phase modes. The $11^{\text {th }}$ International Forum on Strategic Technology (IFOST): proceedings. Novosibirsk, June 1-3, 2016. pp. 140-144.

26. Vajda I., Glazyrin A., Ustinova I., Bolovin E. Influence of Design Methods a Discrete Model of Separately Excited DC Motor on Parameters Estimation. Acta Polytechnica Hungarica, 2018, vol. 15 , no. 6, pp. 219-233.
27. Gavrilin A.N., Bolovin E.V., Glazyrin A.S., Kladiev S.N., P0lishchuk V.I. Resonant oscillations with a limiting amplitude in a vibration electromagnetic activator. Bulletin of the Tomsk polytechnic university. Geo assets engineering, 2019, vol. 330, no. 1, pp. 201-213. In Rus. D0I: $10.18799 / 24131830 / 2019 / 1 / 70$.

28. Plevkov V.S., Radchenko A.V., Baldin I.V., Radchenko P.A., Goncharov M.E., Batuev S.P. Osobennosti razrusheniya zhelezobetonnykh konstruktsiy pri dinamicheskom nagruzhenii [Features of destruction of reinforced concrete structures under dynamic loading]. Tambov University Review, 2013, vol. 18, Iss. 4, pp. 1578-1579.

29. Ozbolt J., Sharma A., Irhan B., Sola E. Tensile behavior of concrete under high loading rates. Int. J. of Impact Eng., 2014, vol. 69 , no. 5 , pp. $55-68$.

30. Kim J.H., Kim D., Han Heung Nam Strain rate dependent tensile behavior of advanced high strength steels. Materials Science \& Engineering A, 2013, no. 559, pp. 222-231.

31. Shang S., Song Y. Dynamic biaxial tensile-compressive strength and failure criterion of plain concrete. Construction and Building Materials, 2013, vol. 40, no. 2, pp. 322-329.

32. Odnokopylov G.I., Sarkisov D.Yu. Evaluation of breaking load parameters under shock wave loading for critical constructions of oil and gas sector facilities. Bulletin of the Tomsk Polytechnic University. Geo Assets Engineering, 2017, vol. 328, no. 3, pp. 85-95. In Rus.

33. Popov N.N., Rastorguev B.S. Voprosy rascheta $i$ konstruirovaniya spetsialnykh sooruzheniy [Issues of calculation and design of special structures]. Moscow, Stroyizdat Publ., 1980. 190 p.

34. Popov N.N., Rastorguev B.S., Zabegaev A.V. Raschet konstruktsiy na dinamicheskie spetsialnye nagruzki [Calculation of structures for dynamic special loads]. Moscow, Vysshaya shkola Publ., 1992. $319 \mathrm{p}$.

35. Rastorguyev B.S. Obespechenie zhivuchesti zdaniy pri osobykh dinamicheskikh vozdeystviyakh [Ensuring the survivability of buildings with special dynamic effects]. Earthquake engineering. Constructions safety, 2003, no. 4, pp. 45-48.

36. Rastorguev B.S. Primenenie dinamicheskikh gasiteley kolebaniy pri vzryvnykh vozdeystviyakh [Use of dynamic vibration dampers for explosive effects]. Stroitelnaya mekhanika i raschet $s 0$ oruzheniy, 2009, no. 1, pp. 50-57.

37. Vinogradova T.N. Vliyanie raspora na rabotu zhelezobetonnykh balochnykh konstruktsiy pri kratkouremennykh dinamicheskikh vozdeystviyakh. Dis. kand. nauk [Influence of thrust on operation of reinforced concrete girder structures of short-time dynamic effects. Cand. Diss.]. Moscow, 1977. 155p.

38. Zulpuev A.M. Issledovanie napryazhenno-deformirovannogo sostoyaniya zhelezobetonnykh raspornykh plit perekrytiy $v$ zdaniyakh s monolitnymi stenami. Monografiya [Investigation of the stress-strain state of reinforced concrete floor slabs in buildings with monolithic walls. Monography]. Bishkek, Ilim Publ., 2010. $80 \mathrm{p}$.

39. Zulpuev A.M., Baktygulov K. Raschet na prochnost sbornykh zhelezobetonnykh plit perekrytiy, opertykh po konturu [Strength analysis of precast reinforced concrete floor slabs supported along the contour]. Territoriya nauki, 2016, vol. 1, pp. 63-68.

40. Tikhonov I.N. Printsipy rascheta prochnosti i konstruirovaniya armirovaniya balok perekrytiy zdaniy iz monolitnogo zhelezobetona dlya predotvrashcheniya progressiruyushchego razrusheniya [Principles of strength calculation and design of reinforcement of girders of buildings from monolithic reinforced concrete to prevent progressive destruction]. Zhilishchnoye stroitelstvo, 2013, no. 2, pp. 40-45.

41. Tikhonov I.N. Armirovanie zhelezobetonnykh konstruktsiy zdaniy, proektiruyemykh s uchetom vozdeystviya osobykh nagruzok. Dis. Dokt. nauk [Reinforcement of reinforced concrete structures of buildings designed to withstand the effects of special loads. Dr. Diss.]. Moscow, 2015. 337 p. 
42. Huynh L., Foster S., Valipour H., Rendall R. High strength and reactive powder concrete columns subjected to impact: Experimental investigation. Construction and Building Materials, 2015 , vol. 78, pp. 153-171.

43. Kumpyak 0.G., Galyautdinov Z.R., Galyautdinov D.R. Experimental study of beams on yielding supports with thrust. IV International Young Researchers Conference. Youth, Science, Solutions: Ideas and Prospects. Tomsk, 2017. Vol. 143, 6 p.

44. Said A.R.A. Povyshenie nesushchey sposobnosti zhelezobetonnykh konstruktsiy pri vzryunykh vozdeystviyakh. Dis. Kand. nauk [Increasing the bearing capacity of reinforced concrete structures with explosive effects. Cand. Diss.]. Moscow, 1995. 207 p.

45. Popov N.N., Rastorguyev B.S. Raschet zhelezobetonnykh konstruktsiy na deystvie kratkovremennykh dinamicheskikh nagru$z o k$ [Calculation of reinforced concrete structures for short-term dynamic loads]. Moscow, Stroyizdat Publ., 1964. 151 p.

46. Kezmani A., Placidi L., Chiaia B., Kumpyak 0., Maksimov V. 3D Modelling of reinforced concrete slab with yielding supports subject to impact load. European Journal of Environmental and Civil Engineering, 2016, vol. 21, pp. 1-38. DOI: 10.1080/ 19648189.2016.1194330

47. Kumpyak 0.G., Galyautdinov Z.R., Kokorin D.N. Strength of concrete structures under dynamic loading. AIP Conference Proc. Advanced Materials in Technology and Construction. Tomsk, 2016. pp. 59-68.

\section{Information about the authors}

Georgy I. Odnokopylov, Dr. Sc., associate professor, National Research Tomsk Polytechnic University.

Oleg G. Kumpyak, Dr. Sc., professor, Tomsk State University of Architecture and Building.

Zaur R. Galyautdinov, Cand. Sc., associate professor, Tomsk State University of Architecture and Building.

Daud R. Galyautdinov, postgraduate student, Tomsk State University of Architecture and Building.
48. Elfetori F.A. Experimental Testing of Composite Tubes with Different Corrugation Profile Subjected to Lateral Compression Load. Engineering and Technology International Journal of Mechanical, Industrial Science and Engineering, 2013, vol. 7, no. 2, pp. 10-15.

49. Fan Z., Shen J., Lu G. Investigation of Lateral Crushing of Sandwich Tubes. The Twelfth East Asia-Pacific Conference on Structural Engineering and Construction Procedia Engineering. Hong Kong, 2011. No. 14, pp. 442-449.

50. Lion K.H., Amir R.A.G., Prasetyo E., Khairi Y. Impact Energy Absorption of Concentric Circular Tubes. WSEAS transactions on applied and theoretical mechanics, 2009, vol. 4, no. 3, pp. $95-104$.

51. Lipa S., Kotełko M. Lateral impact of tubular structure - theoretical and experimental analysis. P. 1 - Investigation of single tube. Journal of theoretical and applied machanics, 2013, vol. 51, no. 4, pp. 873-882.

52. Somya P., Chawalit T., Umphisak T. An Analysis of Collapse Mechanism of Thin-Walled Circular Tubes Subjected to Bending. Proc. of World Academy of Science: Engineering \&Technology, Dec. 2007, vol. 36, pp. 329-334.

Received: 28 February 2019. 